\title{
Integrative versus Conventional Therapy of Chronic Otitis Media with Effusion and Adenoid Hypertrophy in Children: A Prospective Observational Study
}

\author{
Henrik Szőke ${ }^{a}$ Márta Maródi ${ }^{b}$ Zsuzsa Sallay ${ }^{c}$ Balázs Székely ${ }^{d}$ Martin-Günther Sterner ${ }^{\mathrm{e}}$ \\ Gabriella Hegyi ${ }^{a}$
}

a Faculty of Health Sciences, Doctoral School, University of Pécs, Pécs, Hungary;

${ }^{b}$ Department of Otolaryngology, Szt. Borbála Hospital, Tatabánya, Hungary;

cFaculty of Medicine, Semmelweis University, Budapest, Hungary;

${ }^{\mathrm{d}}$ Master of survey-statistics, ELTE TÁTK University, Budapest, Hungary;

e Medical Clinics I, Klinikum Niederlausitz, Lauchhammer, Germany

\section{Keywords}

Chronic otitis media with effusion - Adenoid hypertrophy . Impaired hearing . Pneumatization - Integrative medicine . Conventional medicine · Surgical intervention · Antibiotics . Analgesics

\section{Summary}

Background: Chronic otitis media with effusion (COME) and adenoid hypertrophy (AH) are common entities in the pediatric population. The conventional treatment approach (conventional medicine; COM) involved mainly surgery after a period of close observation. In this study, we aimed to introduce an integrative, non-invasive approach (integrative medicine; IM) for $\mathrm{COME}, \mathrm{AH}$, and associated episodes of recurrent acute otitis media, and compared outcomes with conventional treatment. Methods: We conducted a prospective, non-randomized study in an integrative primary care pediatric practice and a conventional pediatric otolaryngological clinic, where treatment modality was determined by patient preference. Out of a total 101 patients aged 1-8 years, integrative therapy was chosen by 46 , and conventional treatment by 55 . All patients had COME and $\mathrm{AH}$ diagnosed by an otolaryngologist and had moderate to severe hearing impairment. COM treatment was based on close observation over time, nasal decongestants and surgical intervention. In contrast, the IM involved a complex personalized approach with non-invasive interventions, non-allopathic medications, diet and patient education. Results: The number of surgical interventions (adenoidectomy, pressure-equalization tube insertion, myringotomy) was significantly less in the IM cohort (1 of 28 vs. 15 of 35 in the COM group, $p<0.001$ ). The frequency of antibiotic use was significantly less in the IM group $(p<0.001)$. The frequency of analgesic use was also significantly less in the IM group $(p=0.029)$. Improvement in tympanometric measures (normal A-type curve) was higher in IM patients compared to expected spontaneous remission during the observation period. Improvement in audiometric measures (intact hearing) of IM patients was also higher than expected compared to spontaneous remission during the observation period. Conclusion: Compared to conventional treatment, integrative treatment of patients with COME and AH showed significantly lower invasive surgical intervention rates and significantly decreased antibiotic and analgesic use. The integrative treatment was effective, safe and well tolerated.

\section{Schlüsselwörter}

Chronische Otitis media mit serösem Erguss · Adenoide Hypertrophie - Hörverlust . Pneumatisation - Integrative Medizin . Konventionelle Medizin · Chirurgische Intervention · Antibiotika . Analgetika

\section{Zusammenfassung}

Hintergrund: Chronische Otitis media mit serösem Erguss (COME) und adenoide Hypertrophie (AH) sind häufige Erkrankungsbilder im Kindesalter. Die konventionelle Standarttherapie führt nach einer Beobachtungszeit (watchful waiting) in der Regel häufig zu operativen Maßnahmen. In dieser Studie stellen wir einen integrativen, nichtinvasiv orientierten Behandlungsansatz (integrative medicine; IM) für COME, $\mathrm{AH}$ und assoziierte Episoden von rezidivierender akuter Otitis media vor und vergleichen dessen Ergebnisse mit der konventionellen Behandlung (conventional medicine; COM). Methoden: Wir gestalteten eine prospektive, nichtrandomisierte Studie in einer integrativmedizinischen pädiatrischen Praxis und in einer konventionellen pädiatrisch-otolaryngologischen Krankenhaus-Fachambulanz; die Patienten wählten die Therapieform selbst. Von insgesamt 101 Patienten im Alter von 1-8 Jahren wählten 46 Patienten eine integrative, 55 eine konventionelle Therapie. Die Diagnose der COME und $\mathrm{AH}$ aller Patienten war durch einen Hals-Nasen-Ohren-Facharzt gestellt. Der Hörverlust war mittel- oder schwergradig. Die COM basierte auf Zuwarten unter Beobachtung, abschwellenden nasalen Maßnahmen und chirurgischen Interventionen. Im Gegensatz dazu wurde die IM als ein personalisierter, komplex-systemischer Ansatz durchgeführt, die nichtinvasive Maßnahmen, nichtallopathische Medikation, Diät und Patientenedukation umfasste. Ergebnisse: Die Anzahl chirurgischer Interventionen (Adenoidektomie, PET-Insertion, Myringotomie) war signifikant geringer unter IM (IM: $\mathrm{n}=1$ von 28; COM: $\mathrm{n}=15$ von $35 ; \mathrm{p}<0,001)$. Die Häufigkeit antibiotischer Therapien war in der IM-Gruppe signifikant niedriger $(p<0,001)$. Die Häufigkeit analgetischer Therapien war in der IM-Gruppe signifikant niedriger $(p=0,029)$. Während des Beobachtungszeitraums verbesserten sich die tympanometrischen (normale A-Typ-Kurve) sowie die audiometrischen Messungen (intaktes Hörvermögen) in der mit IM behandelten Patientengruppe stärker als die potenzielle Spontanremission. Schlussfolgerung: In der Behandlung von COME und $\mathrm{AH}$ zeigte ein IM-Ansatz im Vergleich zu COM signifikant niedrigere Raten an chirurgischen Interventionen, Antibiotika- und Analgetikaeinsatz. Die IM-Behandlung war wirksam, sicher und wurde gut vertragen.

\section{KARGER}

(C) 2016 S. Karger GmbH, Freiburg
Dr. Henrik Szőke 
Fig. 1. Expected spontaneous regression rates in chronic otitis media. The dots mark historical data, the pecked curve indicates assumed values.

\section{Potential spontaneous regression}

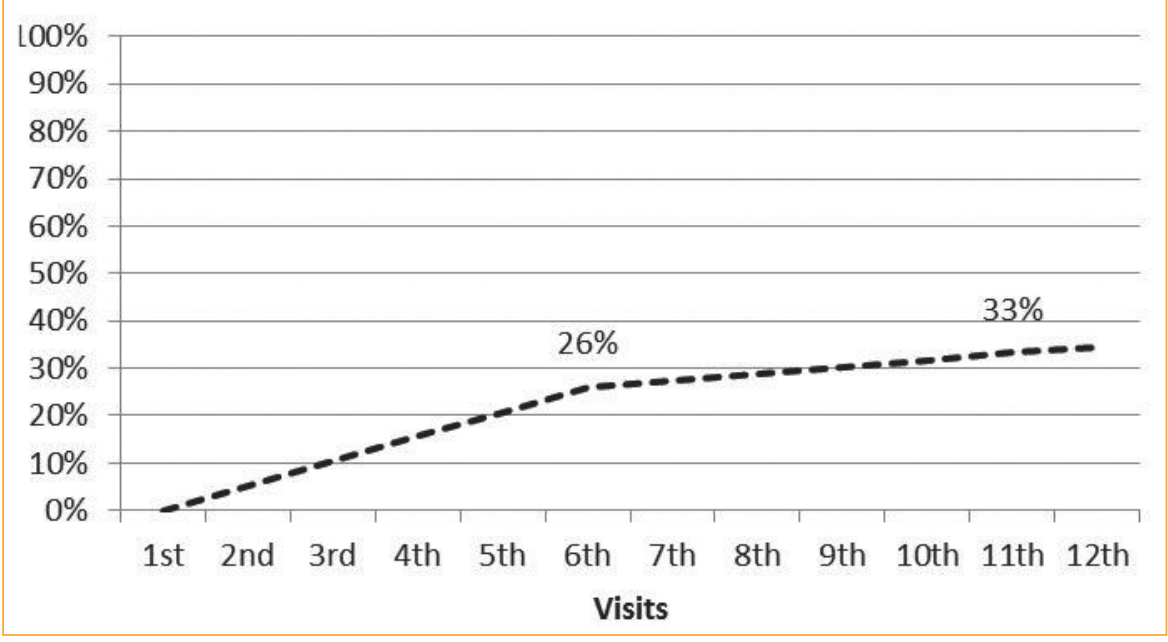

\section{Introduction}

Chronic otitis media with effusion (COME) and adenoid hypertrophy $(\mathrm{AH})$ are common entities in the pediatric population with a bimodal age distribution peaking at years 2 and 5. Children with this condition frequently present with impaired hearing to the pediatric otolaryngological clinic. The disease course typically shows symptoms fluctuating with time [1].

While the diagnosis is usually based upon clinical presentation and an abnormal audiometry or/and tympanometry, endoscopy may also be involved in the diagnostic evaluation.

In general, otitis media of unknown duration has a rate of spontaneous remission of $28 \%$ by 3 months rising to $42 \%$ in 6 months. In contrast, COME has a lower rate, with $26 \%$ resolving in 6 months and only $30-33 \%$ by 1 year after diagnosis (fig. 1.) $[2,3]$. The longer that COME persists, the lower is the rate for spontaneous remission $[4,5]$. Prognosis also depends on age at presentation, with more remission occurring in children younger than 2 or older than 6 [6]. Children between the ages 2 and 6 years tend to have more $\mathrm{AH}$ and, therefore, may need surgery more frequently [7].

Eustachian tube rehabilitation therapy was originally introduced in the 1980s. COME and early retraction pockets are the usual indications [8]. Enhancing muscle strength in the muscles keeping the Eustachian tubes open is the key objective. Randomized controlled trials evaluating the use of nasal balloons for autoinflation revealed a clear benefit [9]. This technique appears safe, simple and effective [10-13]. Autoinflation and external thermal interventions are also widespread and are extensively used in Hungary.

Integrative medicine is used by several primary care physicians to treat upper respiratory or ear infections. However, it has not been formally investigated in the complex setting of chronic otitis media. Integrative medicine often involves the use of anthroposophic medications that are safe and usually well tolerated [14, 15].
Specifically, extracts such as Cydonia fructus glycerinum and citrus lemon fructus have been used in clinical practice for decades [16]. Preparations containing these substances are readily available in the European Union. Their most common indications include rhinitis and specifically allergic rhinitis. This indication is based on their decongestant, adstringent and immunomodulatory, i.e. antiinflammatory and anti-allergic, properties [17-19]. Their efficacy was graded as moderate (GRADE classification) and their application was found to be generally safe [20].

In this study, we hypothesized that using a personalized therapeutic plan in the treatment of COME, AH and associated episodes of recurrent acute otitis media, the integrative medicine approach could reduce the need for surgical interventions, and antibiotic and analgesic use. Additionally, we hypothesized that an integrative approach would represent a safe and effective alternative to conventional treatment.

\section{Material and Methods}

Study Design

We conducted a Good Experimental Practice(GEP)-conform, prospective observational study with non-randomized group assignment and descriptive comparison of outcomes. Groups were non-randomized as patients self-selected under real-world conditions to be included either in the integrative or the conventional therapy arm. The study was conducted in our integrative pediatric practice Clinic (integrative medicine, IM) and a conventional pediatric otolaryngological clinic (conventional medicine, COM) in Hungary.

Ethics Committee approval was granted and the study was performed according to the Declaration of Helsinki. Written informed consent in accordance with local legal requirements was obtained from parents of all patients before study entry.

\section{Patients, Clinical Characteristics}

Between 1 September 2013 and 30 June 2014 we recruited all outpatients presenting with COME and $\mathrm{AH}$ to the pediatric practice $(\mathrm{IM}, \mathrm{n}=46)$ or otolar- 
Table 1. Primary outcome variables

\begin{tabular}{ll}
\hline Variable & \\
\hline $\begin{array}{l}\text { No. of invasive surgical interventions } \\
\begin{array}{l}\text { No. of acute infection episodes } \\
\text { needing antibiotic therapy }\end{array}\end{array}$ & $\begin{array}{l}\text { count } \\
\text { no. during observation period (local and systemic) }\end{array}$ \\
$\begin{array}{c}\text { No. of acute infection episodes } \\
\text { needing analgesic therapy }\end{array}$ & no. during observation period (local and systemic) \\
$\begin{array}{c}\text { Tympanometric measurement } \\
\text { with evaluation of worse ear }\end{array}$ & $\begin{array}{l}\text { A-type curve: normal pressure } \\
\text { C- or D-type curve: under- or overpressure }\end{array}$ \\
Budiometric measurement & $\begin{array}{l}\text { B-type curve: low admittance } \\
\text { normal hearing: }-10 \text { to }-20 \mathrm{~dB} \\
\text { sith evaluation of worse ear }\end{array}$ \\
& $\begin{array}{l}\text { middle hearing loss: }-50 \text { to }-60 \mathrm{~dB} \\
\text { severe hearing loss: } \geq 60 \mathrm{~dB}\end{array}$ \\
\hline
\end{tabular}

Table 2. Secondary outcome variables

\begin{tabular}{|c|c|}
\hline Variable & \\
\hline $\begin{array}{l}\text { Frequency of acute otitis media during } \\
\text { observation }\end{array}$ & number \\
\hline Parents' report on treatment outcome & \\
\hline nasal congestion & subjective scale: $1=$ none, $2=$ moderate, $3=$ severe \\
\hline hearing & subjective scale: $1=$ good, $2=$ moderate, $3=$ bad \\
\hline Adherence to therapy & subjective scale: $1=$ good, $2=$ moderate, $3=$ bad \\
\hline Median time of follow-ups & days \\
\hline $\begin{array}{l}\text { Mean no. of days counted from first visit } \\
\text { in follow-up period }\end{array}$ & days \\
\hline Participation at visits & no. of patients, $\%$ \\
\hline
\end{tabular}

yngological clinic (COM, $\mathrm{n}=55$ ), who were willing to participate in the study $(\mathrm{n}=101)$. Patients self-selected in terms of group assignment and were included either in the integrative or the conventional therapy arm. Per definition, chronic otitis media was diagnosed when symptoms had persisted for at least 3 months. AH was diagnosed by a pediatric otolaryngologist.

Additional inclusion criteria were baseline age of $1-8$ years, and moderate (30-40 $\mathrm{dB}$ on the less affected ear) or severe (over $40 \mathrm{~dB}$ on the less affected ear) hearing loss with abnormal findings in tympanometry at least once during the first 3 visits. Children with anatomical abnormalities (e.g. cleft palate), congenital syndromes (e.g. Down's syndrome), concurrent illnesses requiring continuous medical treatment (e.g. cystic fibrosis) and previous otolaryngological surgical interventions were excluded. Patients lost to follow-up completing less than 3 monthly visits after diagnosis were also excluded from statistical evaluation as they did not fulfill required eligibility criteria.

Baseline parameters included age, type of delivery (cesarean section vs. vaginal), prior number of antibiotic treatments per year, prior number of analgesic treatments per year, prior number of acute otitis media per year, prior indication of adenoidectomy by an otolaryngologist. All patients were followed up by monthly visits over a period lasting at least 1 year to a maximum of 400 days. Data collection was also stopped at the day of surgical intervention if performed. Each initial visit lasted about $40 \mathrm{~min}$, while about $20 \mathrm{~min}$ was usual for follow-up visits.

\section{Treatments: COM Group}

In both groups, the primary aim of therapy was to minimize hearing loss through improvement of nasal breathing, better pneumatization of Eustachian tubes and size reduction of AH. Primary outcome variables for both groups are detailed in table 1. Secondary outcome variables for both groups are detailed in table 2 .

In the COM group, treatment was performed according to the Hungarian guidelines released in 2008 [21] and updated in 2010 [22]. Based on these guidelines, adenoidectomy was the standard surgical intervention. These guidelines differ from the German guidelines updated in $2012[23,24]$ and the guidelines of the American Academy of Pediatrics (AAP) and American Academy of Family Physicians (AAFP) and their updates [25-27]. According to the latter guidelines, active surveillance or 'watchful waiting' is recommended for at least 3 months with monthly audiometry to assess hearing. Antibiotics, decongestants, antihistamines and steroids are not recommended as a routine treatment for COME. Otherwise healthy children with COME persisting over 4 months are considered for surgery if hearing loss exceeds $40 \mathrm{~dB}$. Tympanostomy with a pressure-equaliziation tube (PET) insertion is recommended for children younger than 4 years of age. Myringotomy alone or adenoidectomy as initial procedures are not recommended. Adenoidectomy plus myringotomy with or without tube insertion is recommended if tympanostomy proves to be ineffective. It is also the preferred initial surgical modality for children over 4 years. We emphasize that the COM treatment of the study followed Hungarian guidelines rather than international recommendations in treating the patients.

\section{Treatments: IM Group}

Treatment for the IM group was based on a complex personalized, non-invasive therapeutic system approach as characterized below. It included the use of local nasal preparations, non-allopathic medications, facilitation of pneumatization, external thermal interventions, parent and patient education and antiallergic medications and/or diet if an allergic condition was present (table 3).

\section{Local Nasal Preparations}

Patients were prescribed nasal spray containing Cydonia fruct. glycerinum extract (APC 3.0): $9 \%$ volume with citrus lemon fruit $2 \%$ volume in $1 \% \mathrm{NaCl}$ solvent 4-5 times a day on both sides. The horizontal application of the nasal spray was a key feature in the application to reach the adenoid and the meatus of the Eustachian tube more successfully. 
Table 3. Therapeutic elements of integrative method for chronic otitis media Therapeutic elements of IM

Local nasal preparations

Constitutional non-allopathic medication

Facilitation of pneumatization

External warmth (thermal) interventions

Anti-allergic therapy and/or diet in case of allergy

Parents and patient education

$\mathrm{IM}=$ integrative medicine

Constitutional Non-Allopathic Medications

Berberis/Quarz Glob. WALA (10 g containing Berberis vulgaris e fructibus ferm, 33c Dil. D2 $0.1 \mathrm{~g}$ (HAB, Vs. 33c); Quarz Dil. D19 aquos. $0.1 \mathrm{~g}$, sucrose) $3 \times 5$ globuli per day as oral application over 3-6 months as described in [28]. In our study, no other non-allopathic medications were used.

\section{Facilitation of Pneumatization (Table 4)}

\section{Passive Techniques without Pressure}

Chewing and swallowing were encouraged to intensify the function of peritubular muscles with hard to chew food [29] or chewing gum for several minutes 4-5 times per day [30]. Singing, piping, and yawning were encouraged to allow the soft palate to move upward, the tongue to flatten, the pharynx to dilate, and the hyoid bone to move downward. The Eustachian tubes open at the acme of the yawn.

Exercises to contract the velopharyngeal sphincter involved: (i) tongue movements such as sweeping the palate and moving the tongue backward; (ii) soft palate movements such as contraction of the soft palate, i.e. first stage of swallowing and induced yawning; (iii) protraction and side-to-side movements of the jaw; and (iv) combined movements of the tongue and soft palate, to which jaw movements are then added.

Nasal valve exercises included acquiring awareness to nostril dilation and working against resistance (the parent's thumb and forefinger). Diaphragmatic function can be improved by exercises against pressure from the parent's hand placed on the epigastric region.

\section{Pressure Exercises}

Low-pressure exercises (0-circa $50 \mathrm{~mm} \mathrm{Hg}$ ) included snuffing out a candle, and rolling along a ping-pong ball, and letting a feather fly with 1 opened and 1 pinched nostril. Middle-pressure exercises (circa 50-100 mm Hg) used blowing of party noise makers with well-cleaned noses. High-pressure exercises involving autoinsufflation with strictly cleaned noses used balloon techniques (OTOBAR, Otovent, Pisze orrballon, Hungary), the Valsalva maneuver, and the Misurya maneuver.

\section{External Warmth (Thermal) Interventions}

Local interventions used infrared light or a warming cap (OTO-THERM fülmelegítő gyógysapka) [31] 2-3 times a week for a few minutes on the ears. Systemic interventions included measures such as avoiding areas on the patient's body getting cold, and warm $\left(\mathrm{ca} .40-45^{\circ} \mathrm{C}\right)$ foot baths in fresh $1-1.5 \%$ $\mathrm{NaCl}$ and Zingiber officinale pulvis.

\section{Anti-Allergic Therapy and/or Diet in Case of Allergy}

Consumption of rough cow milk and dairy products was generally restricted to $150 \mathrm{ml} /$ day [29]. In case of IgE or IgG positivity to beta-lactoglobulin, albumin or casein, a complete dairy-free diet was undertaken. No conventional antiallergic treatment was used.

\section{Parental and Patient Education}

Since prior data have shown that such education may enhance compliance and treatment efficacy [32], we undertook a detailed education program with
Table 4. Techniques for facilitation of pneumatization

\begin{tabular}{l}
\hline Used facilitation techniques of pneumatization \\
\hline Passive techniques without pressure \\
Low-pressure exercises (0-circa $50 \mathrm{~mm} \mathrm{Hg}$ ) \\
Middle-pressure exercises (circa $50-100 \mathrm{~mm} \mathrm{Hg}$ ) \\
High-pressure autoinsufflation exercises (circa 100-150 mm Hg) \\
Balloon techniques \\
Valsalva maneuver \\
Misurya maneuver \\
\hline
\end{tabular}

anatomical and physiological-functional illustrations, videos [33], brochures, feed-back sessions, and detailed instructions on all interventional measures, as well as nasal hygiene, and the proper nose-blowing technique.

\section{Statistical Analysis}

Statistical evaluation for small datasets was performed using t-test, ShapiroWilk test of normality, Mann-Whitney test, Independent Samples Median test, Chi-Squared test, and 2-sided Fischer's exact test as appropriate. Comparison of the 2 groups and expected versus actual remissions were performed using IBM SPSS Statistics 22 software and Microsoft Excel. For all analyses, $\mathrm{p} \leq 0.05$ was considered significant.

We used Shapiro-Wilk to test variables for normal distribution. We found that within the groups none of the variables had normal distribution with the single exception of baseline age. Accordingly, we used methods appropriate for non-normal distributions such as the Mann-Whitney test and Fisher's exact test.

\section{Results}

Baseline characteristics for both groups are detailed in table 5 . 101 patients aged 1-8 years were recruited in the study, with 46 selecting integrative therapy and 55 conventional treatments. We had to exclude patients, who did not fulfill eligibility criteria. In the IM group, for 17 of the 18 excluded patients, the reason given was the excessive distance from their home to the praxis; 1 patient had to be excluded because of a central hearing disorder. In the COM group, 16 were excluded for missing at least 3 follow-ups, and 4 as no abnormal finding in tympanometry was found during at least 1 of the first 3 visits.

\section{Primary Outcomes}

The number of invasive surgical interventions (adenoidectomy + PET insertion + myringotomy) was significantly less in the IM patient group ( 1 of $28,3.6 \%$ ) compared to the COM group (15 of $35,42.9 \%$; odds ratio (OR) 20.250, 95\% confidence interval (CI) 2.467-166.229). The difference was statistically significant using the Fisher's exact test, $\mathrm{p}<0.001$ (fig. 2). Similarly, the frequency of antibiotic use was less in the IM group ( 5 of $28,17.9 \%$ ) compared to the COM group (29 of 35, 82.9\%; OR 22.233, 95\% CI $6.018-$ $82.147)$. The difference was statistically significant using the Fisher's exact test, $\mathrm{p}<0.001$ (fig. 3). Frequency of analgesic or antipyretic medication was also less in the IM group (6 of $28,21.4 \%$ ) compared to the COM group (18 of $35,51.4 \%$; OR 3.882 , $95 \%$ CI 1.267-11.898). The difference was statistically significant using Fisher's exact test, $\mathrm{p}=0.020$ (fig. 4 ). 
Table 5. Baseline parameters in the IM versus COM therapy groups

\begin{tabular}{|c|c|c|c|}
\hline Baseline parameter & IM group & COM group & p value ${ }^{a}$ \\
\hline Mean baseline age, months & 56 & 38 & $<0.001$ \\
\hline Tympanometry: abnormal findings ${ }^{\mathrm{b}}, \%$ & 100 & 85 & 0.058 \\
\hline \multicolumn{2}{|l|}{ Audiometry: hearing loss } & \multirow[t]{5}{*}{ n.p. } & \multirow[t]{5}{*}{ n.p. } \\
\hline Light, \% & 50 & & \\
\hline Moderate, \% & 32 & & \\
\hline Severe, \% & 11 & & \\
\hline Data missing, \% & 7 & & \\
\hline Parents' initial report on nasal obstructionc, \% & 96 & 93 & 1.000 \\
\hline Parents' initial self-report on hearing ${ }^{c}, \%$ & 86 & 54 & 0.049 \\
\hline Prior no. of acute otitis media/year & 1.6 & 0.5 & $<0.001$ \\
\hline Prior no. of antibiotic treatments/year & 1.57 & 1.33 & 0.833 \\
\hline Prior no. of analgesic treatments/year & 1.36 & 1.48 & 0.817 \\
\hline Adenoidectomy at baseline, $\mathrm{n}(\%)$ & $7 / 28(25)$ & $7 / 35(20)$ & 0.763 \\
\hline Rate of cesarean section, \% & 14 & 25 & n.p. \\
\hline \multicolumn{4}{|c|}{$\begin{array}{l}\text { 'Reflect differences detected on the } 2 \text {-sided Fisher's exact test and Mann-Whitney test; } \mathrm{p}<0.05 \text { considere } \\
\text { statistically significant. }\end{array}$} \\
\hline \multicolumn{4}{|c|}{${ }^{\mathrm{b}} \mathrm{B}+\mathrm{C}+\mathrm{D}$ type curves, found at least twice during the first 3 visits. } \\
\hline \multicolumn{4}{|c|}{${ }^{c}$ Abnormal $=2$ and 3 on subjective scale of $1-3$. } \\
\hline \multicolumn{4}{|c|}{$\mathrm{IM}=$ integrative medicine; $\mathrm{COM}=$ conventional medicine; $\mathrm{n} . \mathrm{p} .=$ not performed.} \\
\hline
\end{tabular}

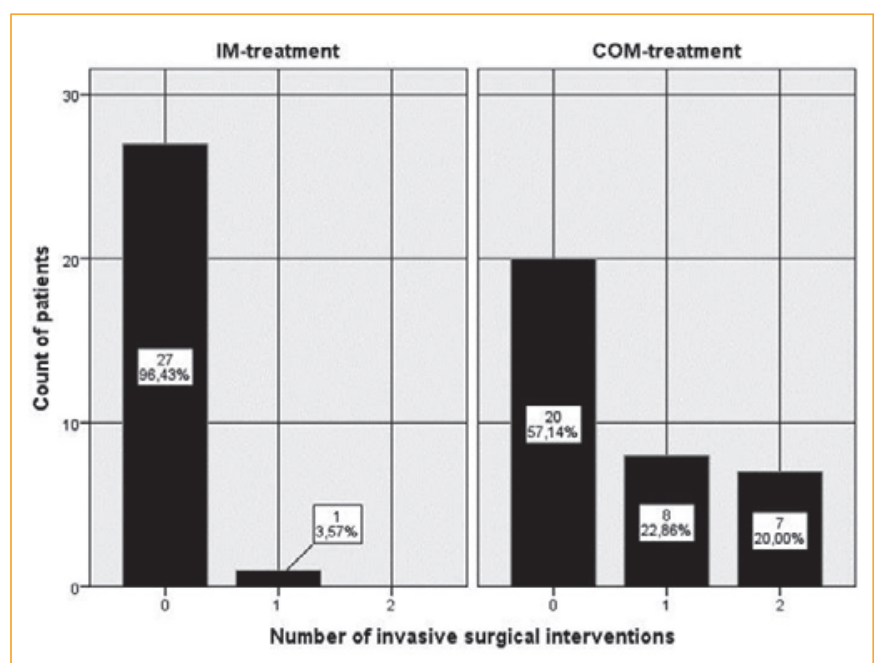

Fig. 2. Number of surgical interventions performed in the 2 groups during the observational period. In the integrative medicine (IM) group, the rate was significantly lower.

Improvement in tympanometric measurement (A-type curve with normal pressure, see also table 2) was higher in IM patients compared to expected spontaneous remission during the observation period (fig. 5). Improvement in audiometric measurement (intact hearing, see also table 2) was higher in IM patients compared to expected spontaneous remission during the observation period (fig. 6).

\section{Secondary Outcomes}

The frequency of acute otitis media during the observation period did not significantly differ between the IM and the COM groups (Mann-Whitney test $\mathrm{p}=0.256$ ) (fig. 7). Objective outcomes as measured by audiometry correlated well with subjective outcomes as reported by parents on most of the visits. A strong and

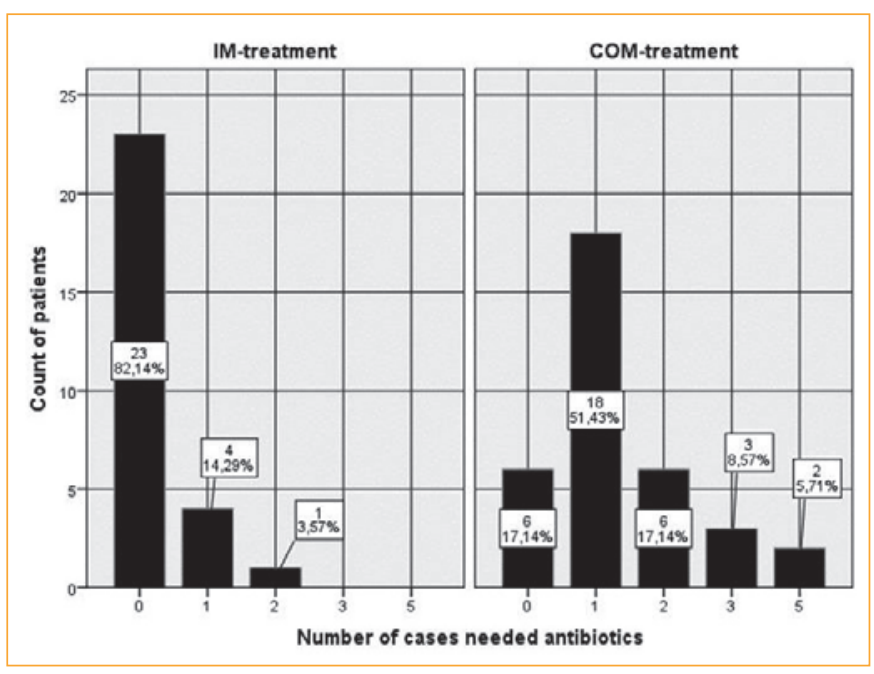

Fig. 3. Antibiotic use in the 2 groups during the observational period. In the integrative medicine (IM) group, the use was significantly lower.

statistically significant correlation was reflected by a Spearman's Rho of $0.54-1.00$ (from $\mathrm{p}<0.001$ to $\mathrm{p}=0.01$ ). On follow-up visits 4 and 5 , this correlation was less marked with a Spearman's Rho of $0.33-0.36$ and were not significant.

Adherence to prescribed therapies was not significantly different (using a self-reported subjective scale of $1=$ good, 2 = intermediate, 3 = bad; Pearson Chi-Squared test $\mathrm{p}=0.181$ ). Median duration of follow-up did not differ significantly (IM 40 days, COM 32 days, Independent Samples Median test $\mathrm{p}=0.843$ ). The mean number of days counted from the first visit to the follow-up period is described in table 6 . Number of follow-ups during the observation period differed significantly between the 2 groups (MannWhitney test $\mathrm{p}<0.001$ ) (fig. 8). 


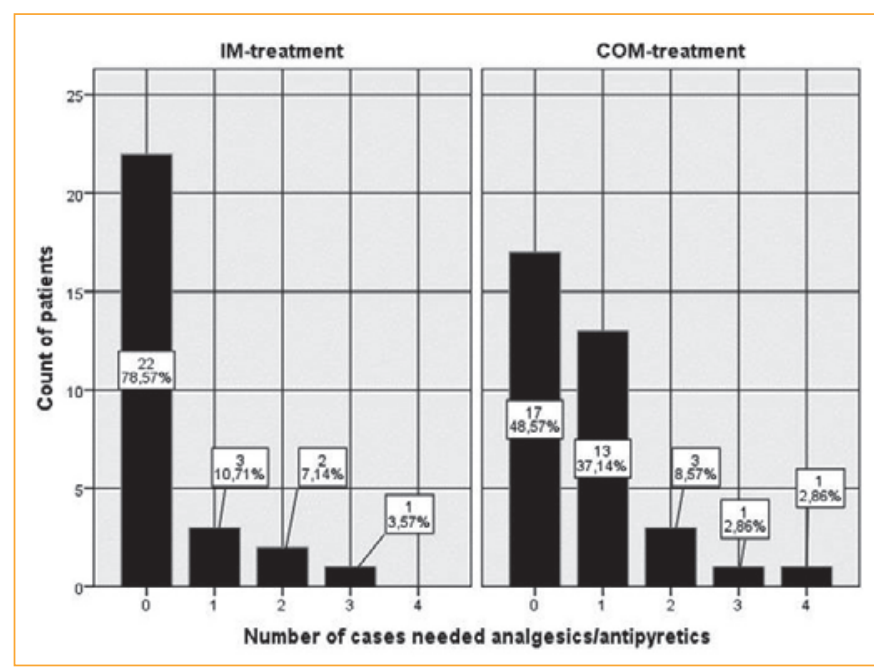

Fig. 4. Analgesic/antipyretic use in the 2 groups during the observational period. In the integrative medicine (IM) group, the use was significantly lower.

Regarding adverse reactions, $2 \%$ of the patients in the IM group reported adverse effects. All adverse reactions were described as mild. No adverse effect report was collected for the COM group. The expected rate of adverse reactions using historical data would have been $6-10 \%$.

\section{Discussion}

\section{Main Findings}

The main findings of this study confirmed our hypothesis that an integrative approach in the treatment of COME and AH is effective in improving hearing loss. It also has the potential to minimize medication use and the number of surgical interventions.

The 2 arms of the study represented 2 different therapeutic settings with a different routine and a different general approach (attitude) by both medical personnel and patients. In fact, in our population both the IM and the COM approaches provided effective therapies. However, while the integrative approach required more efforts in terms of creating and adhering to a more complex treatment plan, requiring multiple non-conventional treatments and more intense patient education, it also induced less adverse reactions than could be expected from conventional therapy considering historical data.

In addition, the integrative approach had the additional benefit of creating more opportunity for personalization and more active parental participation with the caveat that such a proactive approach may not be suitable for all parents and patients [34], although this was not the case in our study.

\section{Additional Findings}

We should emphasize the fact that the overall frequency of invasive interventions in our conventional treatment group was higher than reported previously $[35,36]$. This could be partly explained by the differences between Hungarian and international guidelines detailed in the Materials and Methods section. Specifically, according to Hungarian guidelines $[21,22]$, adenoidectomy is the preferred surgical intervention and it is often performed if nasal decongestants do not provide adequate relief in symptoms. Thus, these regional differences need to be considered when trying to generalize our findings to populations in other countries.

A further finding in our study was a different rate of cesarean section in the obstetric history of patients in 2 groups. This might mirror the different attitude of parents to surgical interventions in each group. Some patients may be more inclined toward surgical interventions when so prompted, while others may tend to adopt a more conservative approach when this option is given to them [37, 38]. We argue that the parents of the patients more inclined to accept the option of cesarean section may have been less likely to use a more conservative approach with IM.

\section{Strengths and Limitations}

Our study has several strengths and limitations. We were able to evaluate several objective and subjective variables in a real-world clinical setting. Due to a long follow-up period and a relatively good adherence to follow-up visits, we were in the position to closely observe the clinical course and were well placed to distinguish between fluctuations in symptomatology compared to true remission.

In terms of selection bias, we evaluated many baseline parameters and these were similar between groups in terms of: (i) pathological tympanometry findings ( $\mathrm{B}+\mathrm{C}+\mathrm{D}$ type curves), (ii) indication of adenoidectomy prior to first visit, (iii) prior number of antibiotic or analgesic treatments per year, and (iv) parents' report on the degree of nasal congestion. However, several important parameters were statistically different between the groups at baseline. Age at presentation, although mostly remaining in the typical range between 2 and 6 years, was nevertheless significantly different between the groups. An important factor in this age difference might have been that parents who opted for integrative treatment might have had the tendency to avoid interventions even before the study due perhaps to a more conservative attitude. Prior number of acute otitis media episodes was also higher in the IM group, presumably for similar reasons. Parents' reports on hearing loss were also more striking in the IM group at baseline. There was also a higher occurrence of cesarean section in the medical history of the COM group patients compared to the IM group ( $25 \%$ vs. $14 \%)$, although both groups had a lower rate than previously reported in the Hungarian population (35\%).

From these differences in baseline characteristics it is clear that the IM group had a disadvantage from the start due to higher age, longer prior symptom duration, and more previous otitis episodes at baseline. This situation tended to diminish the detection of any true benefit from IM as compared to the COM arm. As the IM group was generally disadvantaged, any confounding by baseline imbalances would have worked against the IM group. This natural disadvantage [4-7] and the clear differences in baseline characteristics together made any beneficial baseline confounding so unlikely that no fur- 
Table 6. Mean number of days counted from the first visit during the follow-up period (with 95\% CI)

\begin{tabular}{|c|c|c|c|c|c|c|c|c|c|c|c|}
\hline \multirow[t]{2}{*}{ Treatment } & \multicolumn{11}{|l|}{ Visit } \\
\hline & 2nd & $3 \mathrm{rd}$ & 4 th & 5 th & 6 th & 7 th & 8th & $9 t$ & 10th & 11th & 12th \\
\hline IM & $\begin{array}{l}30 \\
(26-35)\end{array}$ & $\begin{array}{l}63 \\
(54-72)\end{array}$ & $\begin{array}{l}102 \\
(88-115)\end{array}$ & $\begin{array}{l}137 \\
(121-152)\end{array}$ & $\begin{array}{l}177 \\
(168-187)\end{array}$ & $\begin{array}{l}213 \\
(206-220)\end{array}$ & $\begin{array}{l}246 \\
(236-255)\end{array}$ & $\begin{array}{l}276 \\
(267-285)\end{array}$ & $\begin{array}{l}312 \\
(302-322)\end{array}$ & $\begin{array}{l}351 \\
(340-362)\end{array}$ & $\begin{array}{l}393 \\
(379-408)\end{array}$ \\
\hline COM & $\begin{array}{l}27 \\
(19-34)\end{array}$ & $\begin{array}{l}53 \\
(43-62)\end{array}$ & $\begin{array}{l}86 \\
(71-100)\end{array}$ & $\begin{array}{l}125 \\
(103-146)\end{array}$ & $\begin{array}{l}172 \\
(156-189)\end{array}$ & $\begin{array}{l}195 \\
(178-212)\end{array}$ & $\begin{array}{l}252 \\
(216-288)\end{array}$ & $\begin{array}{l}281 \\
(250-311)\end{array}$ & $\begin{array}{l}316 \\
(293-338)\end{array}$ & $\begin{array}{l}342 \\
(314-371)\end{array}$ & $\begin{array}{l}386 \\
(371-401)\end{array}$ \\
\hline Total & $\begin{array}{l}29 \\
(24-33)\end{array}$ & $\begin{array}{l}58 \\
(52-64)\end{array}$ & $\begin{array}{l}93 \\
(84-103)\end{array}$ & $\begin{array}{l}131 \\
(119-143)\end{array}$ & $\begin{array}{l}175 \\
(167-184)\end{array}$ & $\begin{array}{l}206 \\
(198-214)\end{array}$ & $\begin{array}{l}248 \\
(237-259)\end{array}$ & $\begin{array}{l}278 \\
(267-288)\end{array}$ & $\begin{array}{l}313 \\
(303-324)\end{array}$ & $\begin{array}{l}348 \\
(337-359)\end{array}$ & $\begin{array}{l}391 \\
(381-401)\end{array}$ \\
\hline
\end{tabular}

$\mathrm{CI}=$ confidence interval; $\mathrm{IM}=$ integrative medicine; $\mathrm{COM}=$ conventional medicine .

Fig. 5. Improvement in tympanometry in the integrative medicine (IM) group was higher than expected spontaneous regression.

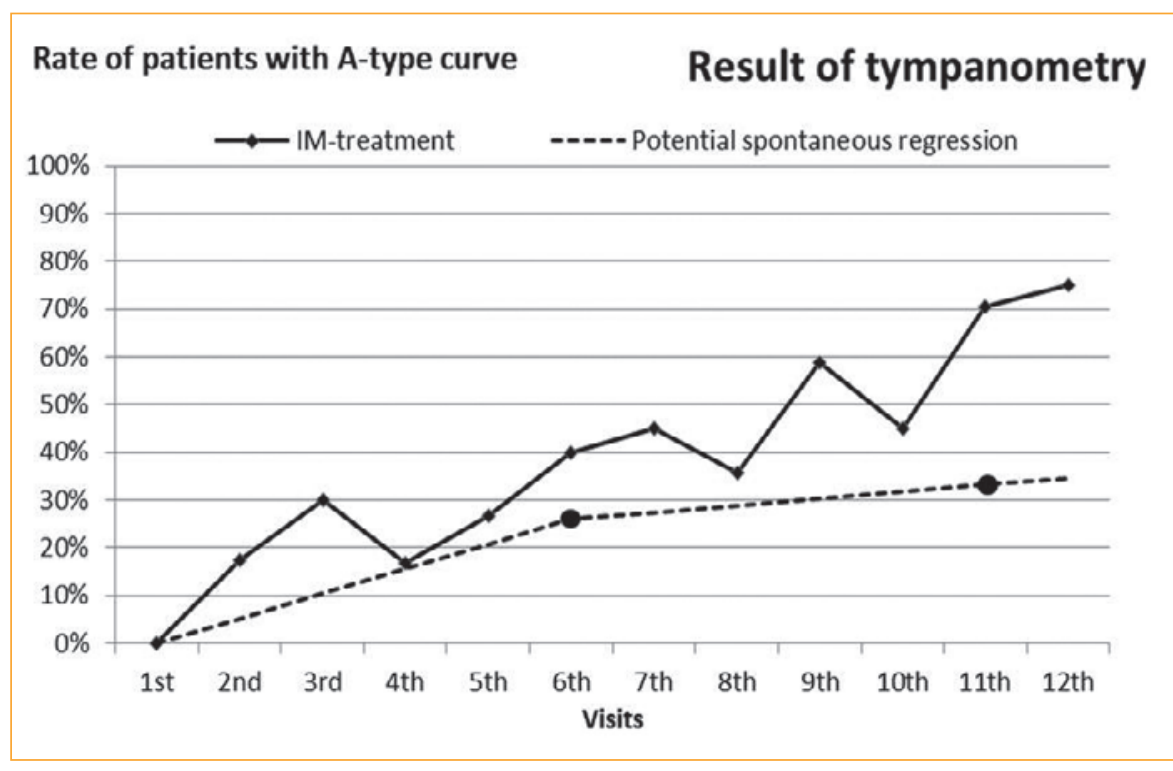

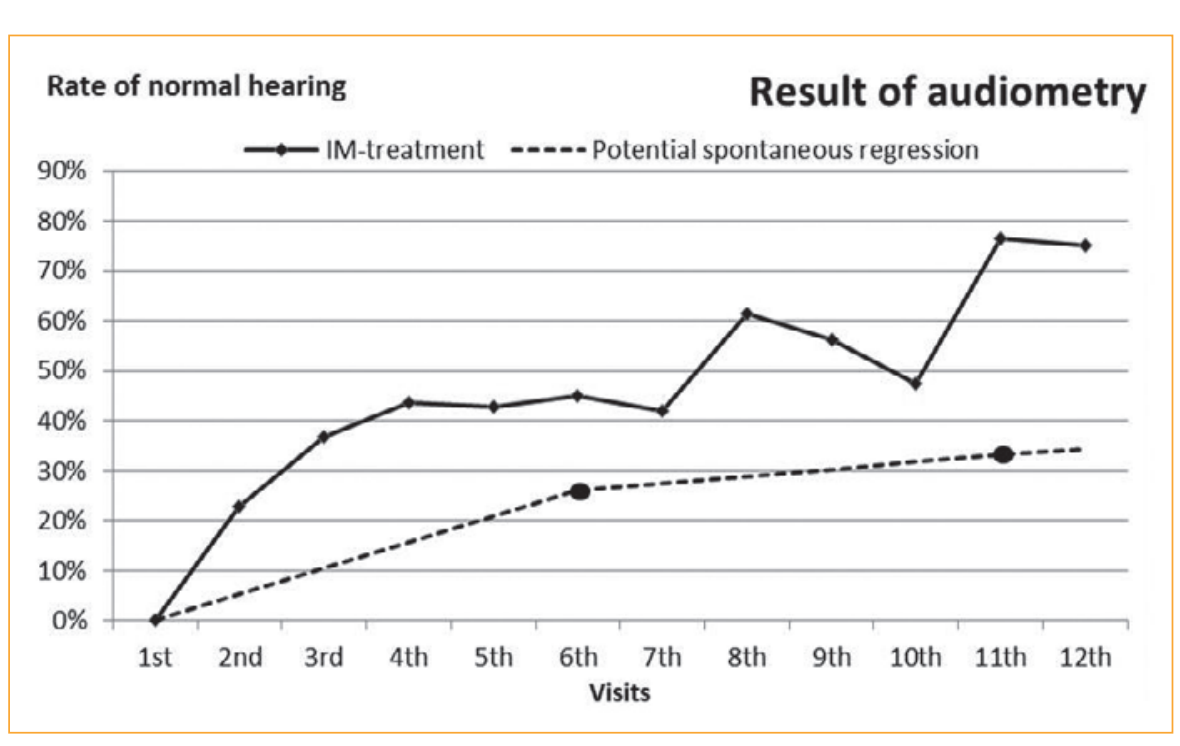

Fig. 6. Improvement in hearing in the integrative medicine (IM) group was higher than expected spontaneous regression. ther measures were needed to exclude them. Adherence to therapy was similar in the 2 groups; the number of follow-ups was higher in the IM group, although relatively good in both groups, further reducing confounding effects of miscellaneous factors.
In terms of attrition bias, a number of patients had to be excluded from both groups due to non-appearance at follow-up visits. In fact, this was the reason for nearly all of the patients being excluded. In the IM group, 18 patients were excluded due to non- 


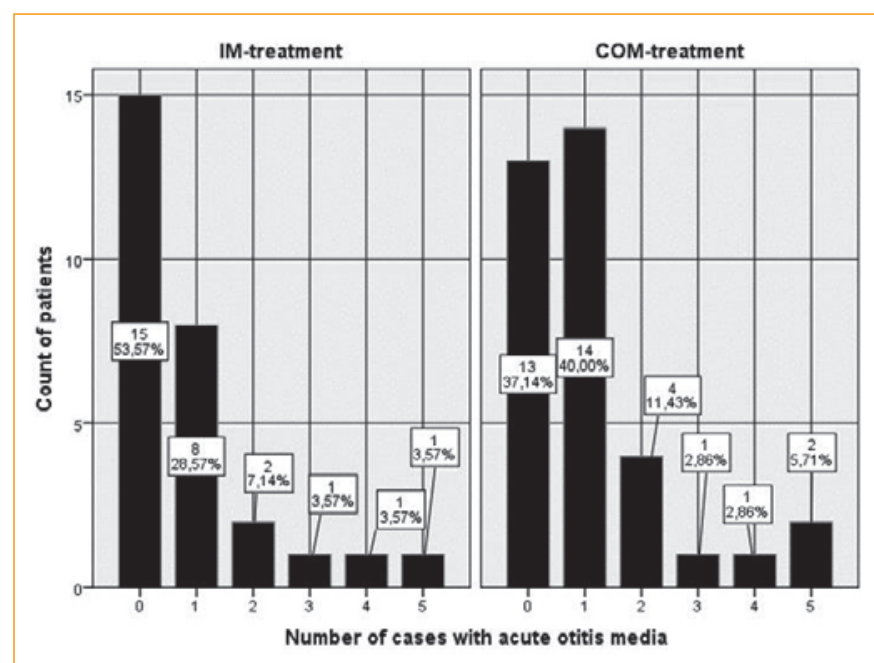

Fig. 7. The number of acute otitis media episodes in the 2 groups during the observational period. The number of episodes was not significantly different between the groups.

completion of the minimum number (3) of visits; the number of exclusions in the COM group for this indication was similar $(\mathrm{n}=20)$. The exclusion of these patients is unlikely to result in an attrition bias as there were no statistically significant differences between the groups in terms of clinical characteristics of the excluded patients. Specifically, baseline age (IM group: MannWhitney test $\mathrm{p}=0.620$; COM group $\mathrm{p}=0.759$ ), the number of prior surgical interventions (IM group: Fisher's exact test $\mathrm{p}=1.000$; COM group $\mathrm{p}=1.000)$ and the grading of baseline symptoms were all similar. These patients also tended to have similar findings on tympanometric and audiometric evaluations (tympanometric findings IM group: Fisher's exact test $\mathrm{p}=0.642$, COM group $\mathrm{p}=0.068$; audiometric findings IM group: Fisher's exact test $\mathrm{p}=0.163$ ). In addition, all exclusions occurred within the first 3 months of the observation period. This meant overall that prognostic factors for spontaneous remission and treatment outcomes were similar in the 2 groups for both the excluded and the included patients.

Dropouts during the observational period occurred in both groups mainly due to surgical interventions. Dropout rates were widely different, amounting to only 1 of 28 (4\%) after the seventh visit in the IM group, while reaching 14 of 35 (40\%) after a mean of 5.64 visits in the COM group. After surgery, data collection was difficult as patients no longer presented for follow-up in our clinic. This represented the single reason for dropping out. Overall, the attrition bias could be estimated as moderate and was unlikely to affect the main findings of the study.

A detection bias was also present as the COM group had inadequate audiometry and tympanometry data, so we needed historical data to create a base for comparison for IM group measurements (expected/potential spontaneous remission). A further observation/reporting bias was possible as audiometry was measured on the worse ear as reported by the parent, a subjective judgment.

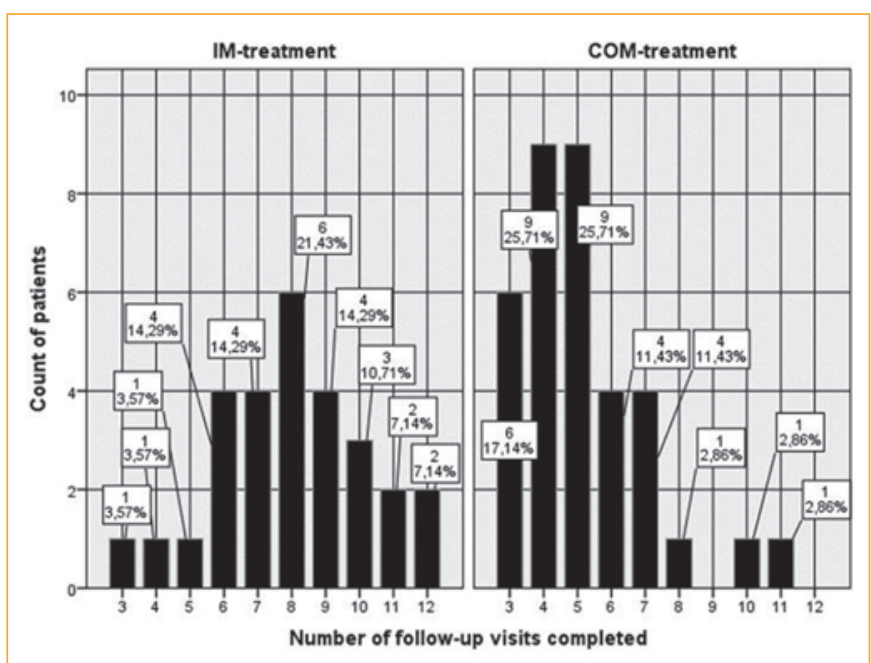

Fig. 8. The number of follow-up appointments kept during the observational period was significantly different in the 2 groups, Mann-Whitney test; $\mathrm{p}<0.001$.

Interpretation and Comparison to Previously Published Work

This study provides a useful addition to previous data reporting a beneficial effect of integrative measures in treating upper respiratory tract infections in children $[34,39]$. Complementary and alternative methods (CAM) are encouraging in this context, although data are insufficient to draw definitive conclusions [40, 41]. There is some research showing that CAM seems to reduce the need for antibiotic and analgesic use [42-46]. However, ours is the first study to introduce a complex IM method in the treatment of chronic otitis media and the first work to evaluate the effectiveness of such a treatment plan with objective outcome measures.

\section{Implications for Practice and Research}

With the caveats mentioned above regarding the generalizability of our present research due to differences in guideline-related practices, our findings seem to suggest the benefit from using alternative treatments during the watchful waiting period that in many cases might eliminate for the need of surgery altogether. These treatments may also obviate the need for antibiotics and analgesics.

As we introduced a quite complex treatment plan with a large number of potentially beneficial components, our study is far too small to distinguish between the individual contributions by each of these components to the total benefit seen in our patients.

Further research is needed with sufficient statistical power to clarify this issue. Some of the examples for potential research is the evaluation of different local nasal preparations or other non-allopathic medications [28], and the individual assessments of pneumatization techniques, external thermal interventions under various climatic and seasonal conditions, anti-allergic therapy and the efficacy of different parent and patient education techniques.

\section{Conclusion}

The complex integrative system approach was effective in reducing hearing loss while also lowering the need for surgical inter- 
vention and the use of analgesics and antibiotics in our pediatric patients suffering from COME and $\mathrm{AH}$ and associated episodes of recurrent acute otitis media. The integrative approach was safe and well tolerated. Further research is needed to evaluate the efficacy of such treatment.

\section{Dedication}

Present scientific contribution is dedicated to the 650th anniversary of the foundation of the University of Pécs, Hungary.

\section{Disclosure Statement}

The study was sponsored in part by a grant from the Lili Kolisko Forschungsstipendium. As this financial contribution was decided upon and received after the completion of the trial, it had no influence on the design or content of the study. Otherwise, the authors have no affiliations with nor involvement in any organization or entity with any financial interest and received no honoraria or educational grants; they did not participate in speakers' bureaus or are employed as consultants; they have no membership, employment, stock ownership or other equity interest, expert testimony or patent-licensing, or non-financial interest including personal or professional relationships or affiliations that are relevant to the subject of or materials discussed in the manuscript.

\section{References}

1 National Collaborating Centre for Women's and Children's Health (UK): Surgical Management of Otitis Media with Effusion in Children: Clinical Guideline. London, RCOG Press, 2008.

2 Rosenfeld RM, Kay D: Natural history of untreated otitis media. Laryngoscope 2003;113:1645-1657.

3 Rovers MM, Straatman H, Ingels K, et al: The effect of short-term ventilation tubes versus watchful waiting on hearing in young children with persistent otitis media with effusion: A randomized trial. Ear Hear 2001;22: 191-199.

4 Tos M, Holm-Jensen S, Sorensen CH, Mogensen C: Spontaneous course and frequency of secretory otitis in 4-year-old children. Arch Otolaryngol 1982;108:4-10.

5 Thomson J, Tos M: Spontaneous improvement of secretory otitis: A long term study. Acta Otolaryngol 1981;92:493-499.

6 Meistrup-Larsen KI, Andersen MS, Helweg J, et al: Variations in tympanograms in children attending group-care during a one-year period. ORL J Otorhinolaryngol Relat Spec 1981;43:153-163.

7 Saffer M, Silva DB, Peduzzi FD, Avila F: Otitis media with effusion: Expectant management. J Pediatr 2000; 76:407-412.

8 Tavernier L, Chobaut JC: Eustachian tube rehabilitation therapy: Indications, techniques, and results, Fr ORL, 2006. 2006(91): p. 241-248., www.rforl.com/pdf/ uk0691002.pdf.

9 Rosenfeld RM, Culpepper L, Doyle KJ, et al: Clinical practice guideline: Otitis media with effusion. Otolaryngol Head Neck Surg 2004;130(5 Suppl):95-118.

10 Stangerup SE, Sederberg-Olsen J, Balle VH: Treatment with the Otovent device in tubal dysfunction and secretory otitis media in children (in Danish). Ugeskr Laeger 1991;153:3008-3009.

11 Ercan I, et al: Long term effect of autoinflation in the treatment of otitis media with effusion. KBB-Forum 2005;4,www.kbb-forum.net/journal/pdf/pdf_KBB_117. $p d f$ (last accessed July 25, 2016)

12 Leunig A, Mees K: Middle ear ventilation with the Otovent latex membrane system. Laryngorhinootologie 1995; 74:352-354.

13 Blanshard JD, Maw AR, Bawden R: Conservative treatment of otitis media with effusion by autoinflation of the middle ear. Clin Otolaryngol Allied Sci 1993;18: 188-192.

14 Hamre HJ, Glockmann A, Schwarz R, et al: Antibiotic Use in Children with Acute Respiratory or Ear Infections: Prospective Observational Comparison of Anthroposophic and Conventional Treatment under Routine Primary Care Conditions. Evid Based Complement Alternat Med 2014;2014:243801.
5 Hamre HJ, Glockmann A, Fischer M, et al: Use and safety of anthroposophic medications for acute respiratory and ear infections: A prospective cohort study. Drug Target Insights 2007;2:209-219.

16 Oppermann A, Rüdinger B, Beckmann C, Meyer U: Local treatment for acute ear and respiratory infections with WALA Aconit ear drops, WALA nasal balm for children and WALA Berdonia nasal spray, www. merkurstab.de/index.php5?page $=108 \nLeftarrow$ lang $=0 \mho$ artikel $=$ 6529, pp 63-67.

17 Gründemann C, Papagiannopoulosc M, Lamyb E, et al: Immunomodulatory properties of a lemon-quince preparation $\left(\right.$ Gencydo $\left.{ }^{\circledR}\right)$ as an indicator of anti-allergic potency. Phytomedicine 2011;18:760-768.

18 Gründemann C, Huber R: Gencydo ${ }^{\circledR}$ to stabilize cells involved in asthma and hay fever. Merkurstab 2011;64: 443-448.

19 Baars EW, Jong MC, Nierop AFM, et al: Citrus/Cydonia compositum subcutaneous injections versus nasal spray for seasonal allergic rhinitis: a randomized controlled trial on efficacy and safety. ISRN Allergy 2011; 2011:836051.

20 Baars EW: A mixed-method approach in reviewing the effects, safety and working principles of Citrus/Cydonia on hay fever. Eur J Integr Med 2012;4:70.

21 www.eum.hu/download.php? docID $=2242$.

22 Szakmai kollégium, Fül-orr- gégészeti Tagozat és Tanács: Klinikai Irányelvek Kézikönyve, 2011.

23 Wilhelm T, Hilger G, Begall K, et al: S1-Leitlinie 'Adenoide Vegetationen/Rachenmandelhyperplasie'. HNO 2012;60:746-752.

24 Lautermann J, Begall K, Hilger G, et al: · Leitlinie 'Seromukotympanum' - Langfassung. HNO 2012;60: 540-544.

25 Rosenfeld RM, Culpepper L, Yawn B, et al: Otitis media with effusion clinical practice guideline. Am Fam Physician 2004;69:2776, 2778-9.

26 Rosenfeld RM, Shin JJ, Schwartz SR, et al: Clinical Practice Guideline: Otitis Media with Effusion Executive Summary (Update). Otolaryngol Head Neck Surg 2016;154:201-214.

27 Randel, A: AAO-HNSF Releases Guideline on Tympanostomy Tubes in Children. Am Fam Physician 2014; 89:754-761.

28 Soldner G, Stellmann HM: Individuelle Pädiatrie. Stuttgart, WVG Stuttgart, ed 3, p 265.

29 Soldner G, Stellmann HM: Individuelle Pädiatrie. Stuttgart, WVG Stuttgart, ed 3, p 264.

30 Kouwen HB, DeJonckere PH: Prevalence of OME is reduced in young children using chewing gum. Ear Hear 2007;28:451-455.

31 Somi I: www.gyogysapka.hu, 2016.
32 Lee HJ, Park SK, Choi KY, et al: Korean clinical practice guidelines: Otitis media in children. J Korean Med Sci 2012;27:835-848.

33 Mann D: www.youtube.com/watch? v=oi6DdairDIo, 2013.

34 Hamre HJ, Fischer M, Heger M, et al: Anthroposophic vs. conventional therapy of acute respiratory and ear infections: a prospective outcomes study. Wien Klin Wochenschr 2005;117:256-268.

35 Van Den Akker EH, Hoes AW, Burton MJ, Schilder AG: Large international differences in (adeno)tonsillectomy rates. Clin Otolaryngol Allied Sci 2004;29:161.

36 Paradise JL: Tonsillectomy and/or adenoidectomy in children: indications and contraindications, www.uptodate.com/contents/tonsillectomy-and-adenoidectomyin-children-indications-and-contraindications (last accessed July 25, 2016).

37 www.oecd.org/els/health-systems/FOCUS-on-Geographic-Variations-in-Health-Care.pdf (last accessed July 25, 2016).

38 Rossi E, Picchi M, Di Stefano M, et al: The homeopathic choice for children: A qualitative research on the decision making process of the families. Homeopathy 2015; 104:176-181.

39 Haidvogl M, Riley DS, Heger M, et al: Homeopathic and conventional treatment for acute respiratory and ear complaints: a comparative study on outcome in the primary care setting. BMC Complement Altern Med 2007;7:7.

40 Fixsen A: Should homeopathy be considered as part of a treatment strategy for otitis media with effusion in children? Homeopathy 2013;102:145-150.

41 Bogomilskiĭ MR, Garashchenko TI, Denisova OA: Assessment of the effectiveness of sinuforte used for the combined treatment of rhinosinusitis and exudative otitis media in children. Vestn Otorinolaringol 2010; (4):74-77.

42 MacKay D: Can CAM therapies help reduce antibiotic resistance? Altern Med Rev 2003;8:28-42.

43 Sarrell EM, Cohen HA, Kahan E: Naturopathic treatment for ear pain in children. Pediatrics 2003;111: e574-579.

44 Taylor JA, Jacobs J: Homeopathic ear drops as an adjunct to standard therapy in children with acute otitis media. Homeopathy 2011;100:109-115.

45 Sinha MN, Siddiqui VA, Nayak C, et al: Randomized controlled pilot study to compare homeopathy and conventional therapy in acute otitis media. Homeopathy 2012;101:5-12.

46 Levi JR, Brody RM, McKee-Cole K, et al: Complementary and alternative medicine for pediatric otitis media. Int J Pediatr Otorhinolaryngol 2013;77:926-931. 